ALPHA No 29 Diciembre 2009 (291-301)

ISSN 0716-4254

http://alpha.ulagos.cl

\title{
LA LIBERTAD DE CONCIENCIA EN MIGUEL DE UNAMUNO
}

\author{
Kevin Fagan*
}

"Vencer no es convencer" fueron las últimas palabras públicas pronunciadas el Día de la Raza, 12 de octubre de 1936, en el Paraninfo de la Universidad de Salamanca, por el rector Miguel de Unamuno. ${ }^{1}$ Frente a la arrogancia militar del General Millán-Astray, ${ }^{2}$ su protesta se puede contemplar como la cumbre de la defensa valiente de la libertad de conciencia por un académico contra la fuerza del despotismo. ${ }^{3}$

¿Qué quiso decir Unamuno? Una sucesión de escritos desde sus años juveniles hasta su muerte en su "cárcel desdichosa" (Cancionero, 1754) ${ }^{4}$ nos ofrece la clave respecto a lo que Unamuno mismo pronunció ese día en plena guerra "incivil" española. ${ }^{5}$ Al lado de sus palabras, buscamos al "hombre de carne y hueso”, según manifiesta en el Sentimiento trágico (1999: Cap. 1). En nuestra investigación de las reflexiones de Unamuno sobre la vida y la verdad, la religión y la ideología, la conciencia y la autoridad, perseguimos esa inteligencia viva e inquisidora con la cual escribió, discutió y actuó. Por tanto,

\footnotetext{
${ }^{1}$ Unamuno (1864-1936) había sido nombrado Rector de la Universidad de Salamanca, España, por primera vez en 1901. Aunque dedicado a las letras, siempre sintió el deber de pronunciarse sobre temas sociales, religiosos y políticos. Así fue destituido en 1914 por su postura crítica frente a la Primera Guerra Mundial. De vuelta como vicerrector en 1921, sus expresiones negativas hacia la dictadura de Primo de Rivera le merecieron el exilio en 1924 a la isla de Fuenteventura (Canarias). Proclamó la II República en Salamanca en 1931, siendo nombrado Rector por el nuevo gobierno y Rector vitalicio en 1933. En 1936 fue primero destituido por el lado republicano (o rojo) y después por el lado fascista (o azul). Cfr. El resentimiento trágico de la vida (1991:35-41).

${ }^{2}$ José Millán-Astray fue uno de los generales más activos en la planeación del levantamiento militar de julio de 1936 contra el gobierno republicano constitucional. Sus ideas políticas se desarrollaron de los principios básicos que guiaron su jefatura de la Legión Extranjera a una justificación elaborada de una “cruzada cristiana” contra los “rojos”. Así llegó a ser Jefe de Prensa y Propaganda del nuevo régimen fascista. Jensen (1992:426).

${ }^{3}$ Unamuno no pensaba hablar durante ese acto de apertura del curso académico, pero frente a la glorificación retórica de la violencia y siendo consciente de los asesinatos de conocidos inocentes, ya no pudo callar más. Sobre este evento. Cfr. Rojas, nota 40 (258-59). También González Egido (129-42); Portillo (397-403); Preston (216-18); Rojas (134-39); Rudd (296301); Salcedo (470-74); Selser (108-12).

${ }^{4}$ El número se refiere a la enumeración en la edición de Senabre. Este poema tiene fecha del 25 de diciembre, 1936. Don Miguel murió el día 31.

${ }^{5}$ Carta del 12 de diciembre, 1936, en Epistolario inédito (1991:351).
} 


\section{Kevin Fagan}

justamente podemos aplicar su propio pensar literario y filosófico, a través de una vida de escritos y discursos, a sus actuaciones personales en pro de la libertad de conciencia. Sus múltiples testimonios en defensa de la libertad de pensamiento y de expresión se basan en una profunda meditación vista en sus libros, poesías y cartas.

Nos interesa analizar el concepto de conciencia en Unamuno como aceptación libre de una decisión personal más que su mismo contenido. Por tanto, sus ideas políticas o religiosas se consideran desde un punto de vista de la conciencia personal. Entonces, no nos fijamos tanto en la fe cristiana de Unamuno cuando escribió El Cristo de Velázquez (1914) sino, más bien, en el hecho de que lo leyó en el Ateneo de Madrid de connotada fama laica (Little, 2002:25-26; Salcedo, 1998:193). De la misma manera, nuestra atención se dirige a cómo Unamuno — en conciencia— vio, juzgó y actuó frente a las autoridades religiosas y políticas de su tiempo y no en cómo tales autoridades vieron a Unamuno.

Aquí, queremos aplicar a Unamuno su propia teoría sobre la presencia de ideas tanto en el escritor como en el lector de sus obras y en su vida, como hizo con el Don Quijote de Cervantes. Por tanto, no solamente podemos leer los textos de Unamuno en el contexto en el cual fueron escritos o dichos y tal cual él los entendió sino, también, darles vida en nuestro tiempo al igual como nosotros los entendemos. Así como quiso Unamuno "resucitar” a don Quijote, queremos revivir a Miguel de Unamuno ("El sepulcro de Don Quijote”, 1996:3). Por tanto, la justificación para estas reflexiones es investigar si las convicciones de Unamuno en su palabra y testimonio conllevan para el lector de hoy en día una teoría coherente sobre la libertad de conciencia. Y, desde allí, queremos deducir unas ideas posiblemente válidas para todo ser humano, independientemente de sus ideas políticas o religiosas. Buscamos al hombre de conciencia, quien pudo decir al final de su vida en una entrevista de mediados de noviembre de 1936: "Primero me echó el Rey, luego Primo de Rivera, más tarde los rojos y ahora los azules. No obstante, yo seguiré diciendo lo que creo que es justo” (Pascual Mezquita, 2003:412).

Estas reflexiones de Unamuno son tanto literarias como filosóficas, basadas en su idea de conciencia como las expone en Mi religión (1967) a la vez que abiertas al método histórico en los acontecimientos como en Paz en la guerra (1995); Recuerdos de niñez y mocedad (1998); el toque personal en el Diario Íntimo (1998) y Cómo se hace una novela (2002); con la realidad existencial en La agonía del cristianismo (1999) y San Manuel Bueno, mártir (2002).

Sigamos un orden cronológico en sus palabras. En su primera novela, Paz en la guerra (1897) Unamuno ve como se quiere identificar la religión católica con el lado carlista en una guerra civil (1873-76) por el poder (Spain, 
en línea 158). En sus Recuerdos de niñez y mocedad cuenta cómo a los diez años fue testigo de aquella guerra al mirar caer una bomba cerca de la casa de un vecino "en mi Bilbao" (1998:72). Paz en la guerra tiene su importancia desde varias perspectivas (Gutiérrez, 1987:141-44). Unamuno se mueve mediante personajes totalmente definidos en un mundo común, considerando en tanto a esos mismos caracteres como individuos, como "hombres de carne y hueso" como después describirá en su gran obra filosófica Del sentimiento trágico de la vida en los hombres y en los pueblos (1993: Cap. 1). En Paz en la guerra la vida tan aburrida de Pedro Antonio, fabricante de chocolates, llega a ser la tragedia de un padre con un hijo perdido en la guerra (1995:259).

La monotonía del quehacer diario en una ciudad anónima se hace personal a través de la muerte, el acontecimiento más individual de todos. Sin embargo, lo más triste para la teoría de Unamuno sobre la conciencia es que esa guerra civil con sus matanzas tiene lugar en el nombre de la Cristiandad y del Príncipe de la Paz. El rol del cura Santa Cruz al apoyar tanto al lado carlista como el lado católico y en interesarse sólo en su propia grey creyente destaca el papel inherente de una religión oficial como determinante sociológico de las creencias y del grupo en boga (1995:101-07). Todo lo cual ve Unamuno como contrario a la aceptación libre y consciente de una fe, la que sea. En esta segunda de las guerras carlistas del siglo XIX, la adhesión personal a un credo se identifica con la aceptación sociológica con un determinado grupo. El ascenso en conciencia ha sido forzado por la violencia de la guerra. La religión, como asunto de salvación del alma individual, se transforma en tema de pertenencia al grupo correcto. El cura, en este caso, siente que él tiene el derecho de fijar la ortodoxia cristiana además de añadir exigencias violentas para los fieles, reduciendo — según él— la salvación solamente a los seguidores de su autoridad. Su deseo de sólo atender a quienes aceptan sus mandatos limita aún más el concepto de la salvación universal de Cristo. Posiblemente, el rechazo del adolescente Unamuno a esa bomba fratricida, disfrazada de cristiana, haya sido semilla de su futuro desencanto con una religión vista como manipulación al servicio del poder o de prestigios personales y partidistas.

A veces, el diario íntimo de una persona revela un lado oscuro de alguien famoso, causando sorpresa y hasta escándalo. En el caso de Unamuno, una lectura de su Diario íntimo no revela ningún detalle sorprendente del escritor o del rector. Más aún, en este caso, hay una tragedia cara a cara - corazón a corazón- para Unamuno. Muere su tercer hijo, Raimundín, nacido en 1896, “que no hace más que reírse” (1998:70) ¿De qué echar mano? ¿De la ciencia, la razón, la fe? Por eso, este tema central de su crisis religiosoagónica de 1897 demostrará la sinceridad de su búsqueda de la fe, a la vez que 


\section{Kevin Fagan}

su libertad de conciencia en no volver a la fe católica de su infancia y juventud.

Siendo universitario, don Miguel se había apartado de su religiosidad tradicional y se había hecho partidario de la filosofía positivista, escribiendo "Buscad el reino de la ciencia y todo se te dará en añadidura” (Zubizarreta, 1960:17). Ahora, su Raimundín se enferma de meningitis aguda y de parálisis parcial. Unamuno mismo cayó al borde de una parálisis, preocupado sobre el estado de su corazón y llegando a caer en una profunda depresión, hasta que una noche de marzo, cuando su esposa se despertó y le gritó "desde el fondo de sus entrañas maternales, sobrehumanas, divinas, arrojándose en mis brazos: —hijo mío_-” según refiere en Cómo se hace una novela (2002:19). Esta autobiografía sobre cómo escribir la novela de su propia vida explica como esas palabras llevan a Unamuno a un sentimiento de su filial "adopción” ante Dios Padre, dándole un momento paradigmático al cual puede unir muchos conceptos tradicionales del cristianismo. El Diario íntimo que guardó Unamuno durante el transcurso de la crisis regresa una y otra vez a la profunda meditación sobre las palabras "Padre Nuestro"

¡Papá! Me llama mi hijo, y si le respondo: ¿Qué? ¡Lo siente, quiere que le diga: querido! Y se arrima a mí, se aprieta contra mí y allí se queda, gozándose en sentir mi arrimo y mi contacto, en tenerme junto a él y volviendo de cuando en cuando sus ojos a los míos para ver que le miro con cariño. Así con nuestro Padre no le pedimos favores de material progreso, ni riquezas, ni salud, ni placeres, ni honores, sino su arrimo y su calor, que nos mire espiritualmente, que nos sintamos bajo su santa providencia (1998:50-51)

El primer impulso de Unamuno fue regresar a la fuerza a la "vieja fe" de su niñez (1998:90). El padre Lecanda, sacerdote amigo de su juventud, aconsejó a Unamuno que evitara la soledad, invitándolo a dejar Salamanca e ir a Alcalá de Henares para la Semana Santa de 1897. En Alcalá, Unamuno leyó libros devotos y los evangelios, se criticó por su soberbia y racionalismo, meditó en Cristo y en su “oculta fe en la Virgen María” (1998:28).

El tono inicial del Diario sugiere, hasta cierto punto, que es casi la historia de un intelectual convertido como es el caso de la Apología del cardenal Newman ${ }^{6}$ o las Confesiones de San Agustín. Unamuno parece, a primera vista, como el hijo pródigo del Evangelio, quien ha abandonado el lenguaje, la moral y la liturgia de la Iglesia de su sangre y de su patria, para

\footnotetext{
${ }^{6}$ La última edición en castellano de la Apología Pro Vita Sua del Cardenal Newman (18011890), donde describe su camino intelectual y existencial hacia la fe católica, tiene prólogo del actual papa, Benedicto XVI (2009).
} 
seguir los intereses intelectuales de la filosofía positivista, y ahora regresa a su fe de antes. Las primeras páginas del Diario tienen frecuentes intentos de expresar en términos conocidos, piadosos y ortodoxos el significado de "hijo mío”, esa exclamación maternal de su esposa.

Pero su esfuerzo humilde y sincero de lograr su salvación dentro de la estructura institucional de la Iglesia Católica en la España de entonces no tuvo éxito. Así, no pudo cumplir con los deberes de la confesión y de comunión anuales de la Pascua. Cumplir sin creer "sería un sacrilegio", confiesa en su Diario Íntimo (61).

Su crisis agónica lo llevó al reconocimiento que ser auténticamente humano significa vivir en la presencia de la muerte, siendo la mortalidad la raíz de nuestra condición. Este tema de la muerte va a estar presente en toda su obra y hasta el final de su vida. Así, en su último acto público, el 12 de octubre de 1936, en la Universidad de Salamanca, denunció al general Millán Astray quien pronunció su grito "Viva la muerte" a favor del odio y matanza de los enemigos de su bando (Salcedo, 1998:472).

En el tema central de la religión frente a la muerte ¿Cómo caracterizó Unamuno el rol de la conciencia? ¿De dónde le vino tal valentía personal frente a una realidad tan fuerte en el ámbito social a la vez que tan personal en la trayectoria intelectual de Unamuno? "Mi religión es buscar la verdad en la vida y la vida en la verdad", escribe Unamuno en su ensayo Mi religión (1907), formulado como respuesta a un anónimo lector chileno quien le preguntó de qué religión era (1967:369). Y, si fuéramos a preguntar hoy lo que no era su religión, encontraríamos en su máxima obra filosófica Del sentimiento trágico de la vida en los hombres y en los pueblos una posible respuesta, "él que basa o cree basar su conducta (...) en un dogma o principio teórico que estima incontrovertible, corre riesgo de hacerse un fanático..." (1999:140). Por eso, en Mi religión, Unamuno afirma su primera paradoja: la libertad de creer hasta el punto de contradecirse en su propia vida (1967:375). La verdad en la vida significa, ante todo, sinceridad y el tiempo necesario para buscarla, conjuntamente con el respeto a la búsqueda del otro. La vida en la verdad implica la disposición de arriesgar todo: la fama, la carrera y la vida, como de hecho aconteció en la vida de Unamuno. Contra la teoría que la religión es necesaria para la moralidad, Unamuno da vuelta al argumento, al estilo de Kant. Si la gente es buena porque hay un cielo o un infierno ¿Qué tipo de carácter moral tienen? De allí la justificación ética de atrocidades inmorales como "cruzadas" o guerras supuestamente santas a favor del cristianismo que vio y vivió al inicio y final de su vida (Cancionero 1754; Gutiérrez, 


\section{Kevin Fagan}

1987:141). ${ }^{7}$ Al mismo tiempo, Unamuno sí se considera cristiano, según expresa en Mi religión

Tengo, sí, con el afecto, con el corazón, con el sentimiento, una fuerte tendencia al cristianismo sin atenerme a dogmas especiales de esta o de aquella confesión cristiana. Considero cristiano a todo el que invoca con respeto y amor el nombre de Cristo, y me repugnan los ortodoxos, sean católicos o protestantes -éstos suelen ser tan intransigentes como aquéllos-queniegan cristianismo a quienes no interpretan el Evangelio como ellos (1967:371).

Esta cita no sólo demuestra la creencia de Unamuno en Cristo y en el cristianismo, a su manera, sino que enfatiza la naturaleza misteriosa de la religión y el carácter personal de la fe de cada persona. Siendo adhesión a un misterio, la religión nunca se entiende del todo, de tal modo que uno se pueda considerar totalmente ortodoxo o al vecino totalmente heterodoxo. De la misma manera, la naturaleza personal de las creencias de cada uno significa que un cuerpo de doctrina aceptado por un grupo no coincide, de por sí, con lo que cree un individuo. Aquí, parece que Unamuno sigue una filosofía de conciencia donde el carácter profundo de la creencia religiosa exige que sea sujeto al examen libre por el ser humano pensante. Por tanto, la afirmación y la fe rígidas se prestan a la posible prescripción del pensamiento e investigación libres. Dado que la fe religiosa es, de por sí, misteriosa y no resulta evidente a toda persona, no se puede exigir ni creencia ni conducta basadas en la religión a otra persona. Más aún, cuando los poderes políticos manipulan las creencias religiosas en pos de sus conveniencias partidistas o personales, se propician los monopolios ideológicos y discriminatorios. Sólo queda un paso para la exclusión o para la persecución del no-creyente o disidente de sus agendas, como pasó con Unamuno. En su obra filosófica principal El sentimiento trágico de la vida en los hombres y en los pueblos, Unamuno ve al filósofo como "un hombre de carne y hueso" (1999: Cap. 1:3-12). Este énfasis en el individuo en contraste con una ideología establecida es, sin duda, una insistencia existencialista en la primacía del individuo contra un espíritu hegeliano en una entidad social e histórica. Sin embargo, el problema del ser humano y de la religión comienza y termina con el tema de la muerte y con la

\footnotetext{
7 "Y yo en mi hogar, hoy cárcel; sueño... en la suerte de España desastrosa; y en la guerra civil que ya en mi infancia...” En 1936, Unamuno primero apoyó la sublevación fascista. Ver "Mensaje de la Universidad de Salamanca a las universidades y academias del mundo acerca de la guerra civil española”, descrita como defensa de "nuestra civilización cristiana de Occidente", con fecha 20 de septiembre, en Salcedo (1998:466-68). Más tarde, el 1 de diciembre, escribe Unamuno: “desgraciadamente no se están siempre empleando para ello métodos civilizados, ni occidentales ni menos cristianos” (Epistolario inédito, 1991:351).
} 


\section{La libertad de conciencia en Miguel de Unamuno}

inmortalidad. Mientras no acepta los argumentos tradicionales racionales a favor de la inmortalidad, Unamuno ve cómo su voluntad siente la necesidad de creer en tal vida, a la vez que su corazón quiere creer en Dios y en la inmortalidad. Pero el abismo sigue entre la razón que lucha con el misterio y la voluntad que acepta la respuesta cristiana. En El sentimiento trágico de la vida en los hombres y en los pueblos, Unamuno concluye que su papel de filósofo es ayudar a todos a "vivir inquietos y anhelantes" (1999:169). Su insistencia en el carácter personal de la fe religiosa le lleva a rechazar toda etiqueta, según expresa en Mi religión

Buscan poder encasillarme y meterme en uno de los cuadriculados en que colocan a los espíritus, diciendo de mí, es luterano, es calvinista, es católico, es ateo, es racionalista, es místico, o cualquier otro de estos motes, cuyo sentido claro desconocen, pero que les dispensa de pensar más. Y yo no quiero dejarme encasillar, porque yo, Miguel de Unamuno, como cualquier otro hombre que aspire a conciencia plena, soy una especie única. "No hay enfermedades, sino enfermos", suelen decir algunos médicos, y yo digo que no hay opiniones, sino opinantes (1967:371).

Por tanto, a priori, Unamuno no acepta ninguna ortodoxia de grupo. Se queda en su opinión aislada y solitaria más que en lo que otros consideran verdadero o falso. No está ni “a la derecha ni a la izquierda” (Cano, 1992:105) ni "fascista ni bolchevique. ¡Yo estoy solo!” (Kazantzakis, 1983:177; Pascual Mezquita, 2003:402). ${ }^{8}$ Es individualista en su fe y en su opinión, precisamente porque considera toda decisión como individual y no puede estar sujeta a la adhesión de grupo. En La agonía del cristianismo (1925) Unamuno sigue buscando la verdad en la vida como una lucha constante por la fe, sobre todo en el misterio de la inmortalidad. La escalera de Jacob es una referencia bíblica, ${ }^{9}$ junto a su repetición de la cita evangélica, "Creo, socorre a mi incredulidad” (Marcos, IX:24) (1999:186). En su vida personal fue rebelde contra la España de trono y altar, pero rezó cada noche, insistiendo en tener una cruz en el pecho (Salcedo, 1998:346-47). Durante su exilio amargo en París, leía un capítulo del Evangelio cada tarde. Sin embargo, no encuentra ninguna razón ni para la inmortalidad ni para la existencia de Dios. De igual forma, rechaza aceptar la "fe del carbonero" unida a la expresión de Santa Teresa de Ávila quien argumentaba: "Eso no me lo preguntéis a mí, que soy ignorante; doctores tiene la Santa Madre Iglesia que os sabrán responder”, que recuerda en su Agonía del cristianismo (1999:226). El siguiente paso, según

\footnotetext{
${ }^{8}$ Entrevista del 20 de octubre, 1936.

${ }^{9}$ Jacob sueña en una escalera que sube desde la tierra hacia el cielo. Génesis (28:11-19).
} 


\section{Kevin Fagan}

don Miguel, para la mayor parte de las iglesias cristianas fue reducir la fe en una persona, en Cristo, en dogmas, leyes y autoridades. El cristianismo institucionalizado ha racionalizado una misteriosa experiencia religiosa personal. Fijar la fe en palabras con la obligación de una sociedad de hacer valer tales creencias puede llegar a excesos de inquisiciones, expulsiones y masacres. La segunda paradoja en la religión de Unamuno es cómo buscar la vida en la verdad. En Cómo se hace una novela (1927) Unamuno escribe que hay quien le aconseja dedicarse a lo suyo, la poesía. Haciendo referencia a la revolución rusa, Unamuno pregunta cuáles eran más poderosos, los escritos de Marx o las armas de Lenin (2002:7). Su propia vida de despedidas, exilios, ridículo, persecución y muerte solitaria demuestran al fin cómo sentía su deber de vivir de acuerdo con lo que creía. La suprema justicia, para Unamuno, es la libertad de la verdad. Distinguiendo la razón de la verdad, Unamuno encuentra toda razón como algo social, mientras la verdad es necesariamente personal. Pero ¿Cuál es el enemigo de esta búsqueda libre de la verdad? Al final, puede ser la presión de las costumbres o de las ideologías sociales, impuestas o por la fuerza, la mentira o la manipulación, que sofocan la investigación y publicación libres de la verdad, según sostiene en su Diario (1998:87). Por tanto, en Cómo se hace una novela Unamuno contesta a los que le aconsejan dejar la política

Que hoy, en mi patria, se trata de luchar por la libertad de la verdad, que es la suprema justicia, por libertar la verdad de la peor de las dictaduras, de la que no dicta nada, de la peor de las tiranías, la de la estupidez y la impotencia, de la fuerza pura y sin dirección (2002:24).

Al final de su vida, en San Manuel Bueno, mártir (1931) Unamuno postula que la fuerza de la religión consiste en ofrecer una respuesta sencilla al gran enigma de la muerte y a la necesidad existencial de creer en la inmortalidad de los nuestros. Por tanto, este misterio doble de la muerteinmortalidad es tanto el inicio de toda filosofía como el sentido profundo de la religión. La fuerza de esta novela se engrandece en el contexto histórico del anticlericalismo violento e intolerante durante la II República ("Delirium furibundum" 1130-31). ${ }^{10}$ Unamuno claramente respeta el derecho del pueblo a creer aunque él no crea. La religión del cura es “consolar a los demás”, según sostiene en San Manuel Bueno, mártir (2002:165). Más aún, parece una

\footnotetext{
${ }^{10}$ El mismo Unamuno que proclamó la República en Salamanca el 14 de abril de 1931 escribe en el año 34: "Y como, fuera de las mandingas constitucionales, no saliese nada, los delirantes furibundos de la revolución... se entregaron, desatraillados a la descompostura de quemar iglesias y conventos indefensos”. Para la evolución de la posición de Unamuno durante la II República. Cfr. Rojas (1995:11-32).
} 
contradicción aparente con su deseo anterior de siempre decir la verdad. Aquí, el cura agnóstico pastorea a su parroquia creyente, es solidario con sus sufrimientos y respetan su fe en la vida eterna. Esta vivencia religiosa está lejos de las cruzadas, o de la guerra carlista descrita en Paz en la guerra (1995) o en la lucha fascista promovida por Millán-Astray. La lucha que él mismo tenía con el problema de la muerte quizás le haya convencido de dejar a la gente en su fe sencilla y alegre. La libertad de conciencia es para todos o no es libertad. San Manuel Bueno, mártir presenta tanto al cura como al pueblo con sus creencias contradictorias en cuanto a la inmortalidad, pero viviendo en paz y en solidaridad. Hacia el final de su vida, Unamuno acaso nos dice que tal es la libertad de creer y de proclamar lo que uno profesa verdadero y ético. Por tanto, vemos cómo — con el paso de los añosUnamuno ha desarrollado un proceso de búsqueda y tolerancia de la verdad propia y ajena. Él siempre ha sido crítico de autoridades religiosas y políticas. Ahora, la autoridad eclesiástica, el cura, debe respetar la fe de su pueblo. En eso, podemos ver una actitud consistente de lucha por la verdad en la vida.

Concluyendo, la libertad de conciencia es para Unamuno una lucha constante por la verdad en libertad, desde la madrugada hasta el atardecer, como Job en la Biblia (Génesis 32;24b-32). Y, precisamente porque la religión es algo o alguien misterioso, "tanto los individuos como los pueblos de espíritu perezoso (...) propenden al dogmatismo (...). La pereza espiritual huye de la posición crítica o escéptica”, afirma en Mi religión (1967:389). Unamuno cree que el pueblo español ha caído en un dogmatismo rutinario, en un catolicismo jurídico o en un liberalismo libre-pensante. Por eso, cree que su papel es el de un Sócrates, despertando a la gente a pensar por su cuenta, antes que tragar la ideología social de los poderes de hecho. "Vencer no es convencer”. La victoria de la fuerza es sólo externa y, por tanto, falsa. La verdad convence, como la vida y la palabra de este escritor y testigo de la

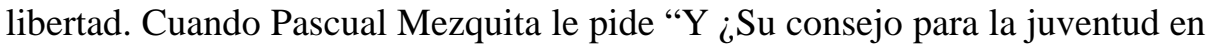
aquel año trágico?”. Su respuesta fue: “Que estudien la Historia de España y formen criterio propio" (2003:399).

\author{
California Polytechnic State University* \\ Modern Languages and Literatures Department \\ 1 Grand Ave. \\ San Luis Obispo, CA 93407 (U.S.A.) \\ kfagan@calpoly.edu
}


Kevin Fagan

\section{BIBLIOGRAFÍA}

CANO, José Luis. "Unamuno y la guerra civil”, en Historia y poesía. Barcelona: Antropos (1992):105-17.

GONZÁLEZ EGIDO, L. Agonizar en Salamanca, Unamuno (julio-diciembre 1936). Madrid: Alianza, 1986.

GUTIÉRREZ, Jesús. "El tema de la guerra civil en Unamuno”. La Chispa 87. Proc. of 8th Conference on Hispanic Languages and Literatures. Tulane U., New Orleans (1987):139-49.

KAZANTZAKIS, Nikos. Spain. Trans. Amy Mims. Berkeley: Creative, 1983. JENSEN, R. Geoffrey. "Jose Millan-Astray and the Nationalist "Crusade" in Spain”, en Journal of Contemporary History. Vol. 27. $\mathrm{N}^{\circ} 3$ (Julio 1992): 425-447.

LITTLE, William. The Velázquez Christ. Poem. Lanham, MD: UP of America, 2002.

NEWMAN, John Henry. Apología Pro Vita Sua. Madrid: Ciudadela, 2009.

PASCUAL MEZQUITA, Eduardo. La política del último Unamuno. Salamanca: Anthema, 2003.

PORTILLO, Luis. “Unamuno's Last Lecture”, in The Golden Horizon (Ed.). Cyril Connolly. New York: University (1955):397-403.

PRESTON, Paul. The Spanish Civil War. Reaction, Revolution, and Revenge. New York: Norton, 2007.

ROJAS, Carlos. ¡Muera la inteligencia! ¡Viva la muerte! Salamanca 1936, Unamuno y Millán Astray frente a frente. Barcelona: Planeta, 1995.

RUDD, Margaret Thomas. The Lone Heretic. New York: Gordian, 1976.

SALCEDO, Emilio. Vida de Don Miguel, Un hombre en lucha en su leyenda. $3^{\text {a }}$ ed. Salamanca: Anthema, 1998.

SELSER, Gregorio. "Unamuno y los militares", "Venceréis pero no convenceréis”, en Cuadernos Americanos 6.257 (1984):103-16.

SPAIN. Encyclopaedia Britannica Online. (27 Apr. 2009). $<$ http://search.eb.com/eb/article-70437>.

UNAMUNO Y JUGO, Miguel de. Cómo se hace una novela. Colección "Sepan Cuantos". 384. México, D. F.: Porrúa (2002):1-40.

------- San Manuel Bueno mártir. Colección "Sepan Cuantos”. 384. México, D.F.: Porrúa (2002):137-78.

------- Del sentimiento trágico de la vida en los hombres y en los pueblos. Colección "Sepan Cuantos". 402. (Ed.) Ernst Robert Curtius. México, D.F.: Porrúa (1999):1-173.

------- La agonía del cristianismo. (Ed.) Ernst Robert Curtius. Colección “Sepan Cuantos”. 402. México, D.F.: Porrúa (1999):175-240.

Diario Intimo. Madrid: Alianza, 1998. 
Recuerdos de niñez y mocedad. Madrid: Alianza, 1998.

------ "El sepulcro de Don Quijote”, en Vida de Don Quijote y Sancho. Colección "Sepan Cuantos”. 417. México, D.F.: Porrúa (1996):3-9.

------ “Cancionero”, en Obras completas. Tomo V. (Ed.) Ricardo Senabre. Madrid: Castro (1995):77-857.

------ "Paz en la guerra”. Obras completas. Tomo I. (Ed.) Ricardo Senabre. Madrid: Castro (1995):1-292.

------- El resentimiento trágico de la vida. Notas sobre la revolución y guerra civil españolas. (Ed.) Carlos Feal. Madrid: Alianza, 1991.

-------Epistolario inédito. (Ed.) Laureano Robles. Madrid: Espasa-Calpe, 1991.

------ “Mi religión”, en Ensayos. (Ed.) Bernardo G. De Cándamo. $7^{\mathrm{a}}$ ed. Tomo 2. Madrid: Aguilar (1967):369-75.

------- “Delirium furibundum”, en Obras completas. (Ed.) Manuel García Blanco. Tomo 8. Madrid: Aguado (1958):1129-31 (27 de junio, 1934).

ZUBIZARRETA, Armando. Tras las huellas de Unamuno. Madrid: Taurus, 1960. 